\title{
DRIVER DROWSINESS DETECTION USING PYTHON
}

\author{
Bhumika Rajput \\ Department of Electrical Engineering \\ Bundelkhand Institute of Engineering and Technology, Jhansi, India
}

\begin{abstract}
When the driver does not get proper sleep, rest or fell sleepy, they sleep while driving and it could be fatal to driver and even the passengers. This issue should have a solution in form of a system in which they can identify drowsiness on the face of a driver and then could ring an alarm so that driver can take necessary actions after that.

The detection is done mainly in three steps, in beginning the system should identify the face and then facial features and then followed by eye tracking. In this we use correlation coefficient template. The extracted eye image and template is then matched so that the system can know if the driver is sleeping or not. The blinking is then recognized and if it fall within a certain range, the alarm will go off.
\end{abstract}

Keywords-Face detection, Eye tracking, Python, Open CV.

\section{INTRODUCTION}

The Driver who is drowsy or sleepy cannot tell when he will fall in micro sleep which is when the pall falls asleep and then wakes up immediately. Due to drowsiness the driver drives actively less. Various studies done around the world states that $30-40 \%$ accidents happen when the driver is drowsy.

Nowadays due to advancement of technology, everyone needs solution that is faster and easier, so that the work becomes less exhausting for employees. Due to modern solution we can see vision based devices everywhere.

For detection of drowsiness, the process involves face detection, detection of eye position and then the blinking pattern of eye. The analysis of face is done by using a "Shape predictor containing 68 landmarks". For the detection of fatigue we use a cam which is probably a webcam in this case which is set on the face of the driver for detection of face and his/her face landmarks to determine the position of eye. For this it must look at all the features of the face and eyes by using self developed image processing. Once the system find the position of eyes, the system will check if the eyes are closed or opened and the rate of close and opening which is calls blinking. If the eyes are closed for a particular time interval then the alarm will go, which will alert the driver.
New and fast methods must be developed for this action of driver as it is very hazardous. Inattention of driver is very dangerous as the driver is not alerted and he/she is not active when driving. This is a major challenge in accident avoidance systems. Many a time driver is distracted due to the passengers or anything on the road, which is also very dangerous as in a fraction of second accident can happen.

\section{WORKING OF THE SYSTEM}

The Driver Drowsiness system is developed using the intrusive machine vision based concepts. In this, a web cam is focused on the face of the driver for the detection his face.

After detection of face it focuses on the eyes and the state of eyes like the closed eyes or opened eyes. The movement of eyes is checked for fatigue detection. And if fatigue is detected, a warning signal is send to the driver so that he can adjust himself.

In this project, I have used python for drowsiness detection. The system deals with a specific part of the body which is the face. The input video is captured using web cam placed in front of the face the driver. If face is not detected after several frames, the system will draw the conclusion of drivers sleeping. OpenCv is used for detection of face and eye with the help of 68 landmarks of face. By using Euclidean eye aspect ratio, it can detect if the eyes are closed or opened.

The system will detect the face and eyes of the driver using the command. Then it will detect if eye is closed or opened. If the time interval of the eyes closed is more than the given time interval, the alarm will go on, warning the driver. if the eyes are opened then the system will goes on tracking the eyes of the driver and it will go on. 


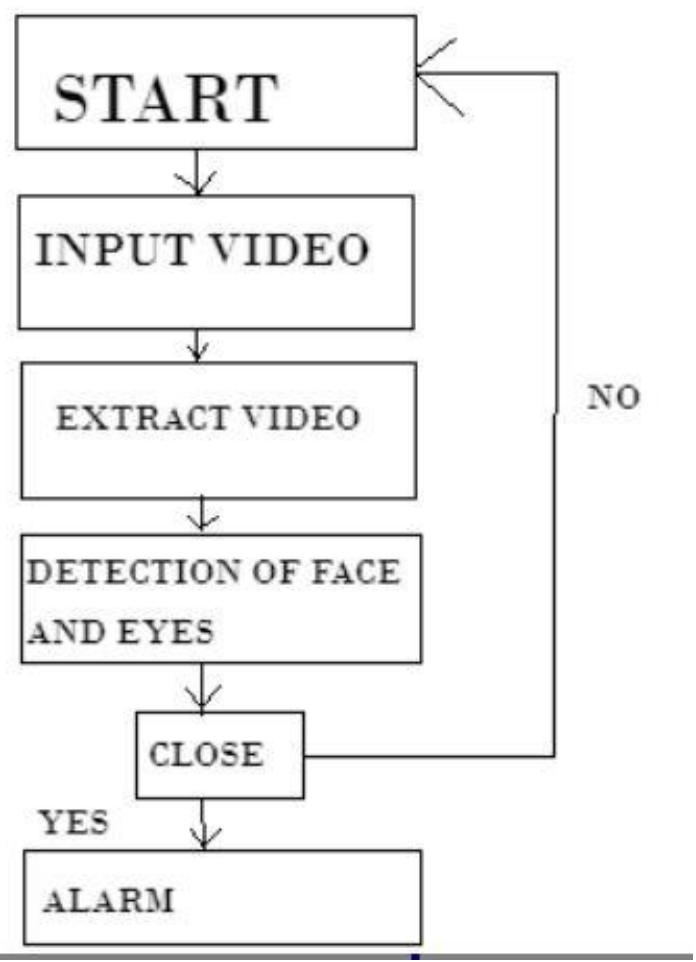

Fig. 1. Flow Chart of the above process

In Fig. 1. Flow cart is made for show the working of the project. The working is, when the user runs the program, the webcam that is placed in front of the driver starts detecting the face and then eyes. Then the program will extract the data from the webcam and then detect if the eyes are closed or opened. If the eyes are closed then the system will play sound so that the driver is awaken. If the eyes are opened then the system will goes on repeating the program. The process will go on.

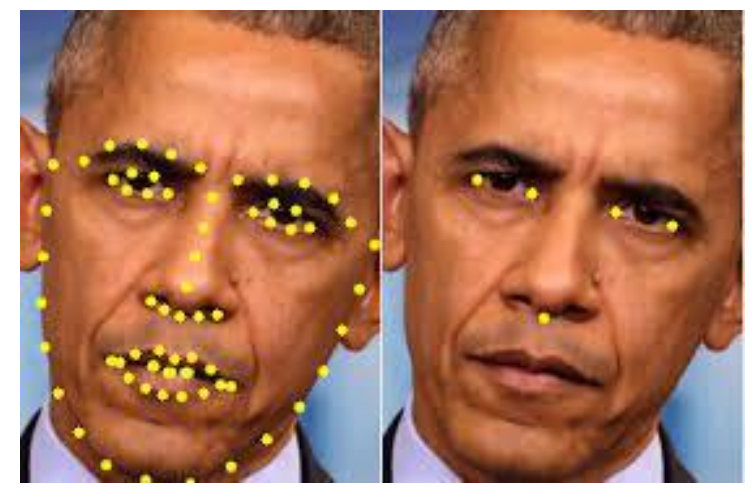

Fig 2. Face landmarks pointing

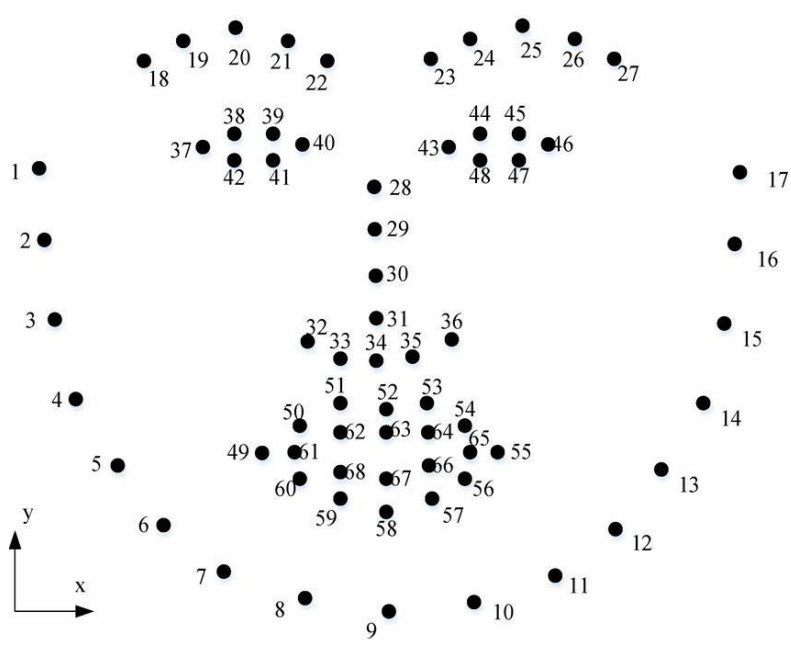

Fig. 3. Haar cascade 68 Landmarks pointers.

For eye detection we used lamdmarks number 40 to 46 as they are the landmarks of the eyes.

\section{REQUIREMENTS}

The Requirements for the above program to be achieved are

1) Anaconda Software

Anaconda is a free and open source distribution of pyrhon and $\mathrm{R}$ programming languages for scientific computing, that aims to simplify package management and deployment.

2) Python

Python 3.6 version is used which support OpenCv and dlib packages for face recognition. Python is comparatively easy languages and it is interpreted and is also a general purpose language.

\section{3) $O p e n C v$}

It is an open source library of programming functions which are mainly used for machine learning and compute vision

\section{4) Dlib}

Dlib is a modern toolkit containing machine learning algorithms and tools for creating complex software in $\mathrm{C}++$ to solve real world problems. Here it is used mainly for face detection and eye detection that is done by pointing the landmarks.

\section{5) Webcam}

To detect face on which the programming is done. 


\section{International Journal of Engineering Applied Sciences and Technology, 2021 \\ Vol. 6, Issue 4, ISSN No. 2455-2143, Pages 299-301 \\ Published Online August 2021 in IJEAST (http://www.ijeast.com)}

\section{6) Play Sound}

It is used to play sound after detecting that the driver is asleep so that he can wake up.

\section{CONCLUSION}

In this way we have implemented the drowsiness detection system using python successfully. The alarm will automatically goes on when the driver's eyes are closed more than the given time interval. He system must be mounted on the vehicle in the real world for the proper execution of driver drowsiness system. This system will help in lowering the accidents which are mostly done due to driver falling asleep while driving.

The system will detect drowsiness by observing eye blinking patterns that is achieved by using Euclidean distance ratio i.e. eye blinking ratio. It is most efficient technique and the whole program is much faster than by using MATLAB.

\section{REFERENCE}

[1] Vandna Saini, Rekha Saini "Driver Drowsiness Detection System and Techniques", IJCSIT, Vol. 5 (3), 2014.

[2] K.Srijayathi, M.Vedachary "Implementation of the Driver Drowsiness Detection System", IJSETR, Volume 2, Issue 9,

September 2013.

[3] Chisty, Jasmeen Gill, "Driver Drowsiness Detection System", IJCST, Volume 3, Issue 4, Jul-Aug 2015.

[4] Divya Chandan, "Drowsiness Detection Using MATLAB", IJCST, Volume 9, Issue 3, March-2018.

[5] Arun Sahayadhas, Kenneth Sundaraj \& Murugappan Murugappan "Detecting Driver Drowsiness Based on Sensors", Sensors, 7

December 2012.

[6] Patil M.N., Brijesh Iyer, Rajeev Arya (2016) Performance Evaluation of PCA and ICA Algorithm for Facial Expression Recognition Application. In: Pant M., Deep K., Bansal J., Nagar A., Das K. (eds) Proceedings of Fifth International Conference

on Soft Computing for Problem Solving. Advances in Intelligent Systems and Computing, vol 436, pp 965-976. Springer,

Singapore. https://doi.org/10.1007/978-981-10-0448-3_81

[7] Mitharwal Surendra Singh L., Ajgar Bhavana G., Shinde Pooja S., Maske Ashish M. "Eye Tracking Based Driver Drowsiness

Monitoring \& Warning System", IJTRA, Volume 3, Issue 3, May-June 2015.

[8] S. Bavkar, B. Iyer and S. Deosarkar, "Rapid Screening of Alcoholism: An EEG Based Optimal Channel Selection Approach," in

IEEE Access, vol. 7, pp. 99670-99682, 2019, doi: 10.1109/ACCESS.2019.2927267.
[9] Oak P., Iyer B. (2020) Specular Reflection Detection for Early Prediction of Cervix Cancer. In: Hitendra Sarma T., Sankar V.,

Shaik R. (eds) Emerging Trends in Electrical, Communications, and Information Technologies. Lecture Notes in Electrical

Engineering, vol 569,pp 683-691. Springer, Singapore

[10] Bavkar S., Iyer B., Deosarkar S. (2020) BPSO Based Method for Screening of Alcoholism. In: Kumar A., Mozar S. (eds)

ICCCE 2019. Lecture Notes in Electrical Engineering, vol 570, pp 47-53. Springer, Singapore. https://doi.org/10.1007/978-981-

13-8715-9_6

[11] Oak P., Iyer B. (2020) Specular Reflection Detection and Substitution: A Key for Accurate Medical Image Analysis. In: Kumar

A., Mozar S. (eds) ICCCE 2019. Lecture Notes in Electrical Engineering, vol 570,pp 223-241. Springer,

Singapore.https://doi.org/10.1007/978-981-13-8715-9_28 